\title{
International Virtual Writing Camp: A Feasible Solution of Prospective Author Training
}

\author{
Dedi Kuswandi ${ }^{1}$, Nurul Murtadho ${ }^{2}$, Syamsul Hadi ${ }^{3}$, Aji Prasetya Wibawa ${ }^{4}$, Roni Herdianto ${ }^{5}$, Ilham Mulya Putra \\ Pradana ${ }^{*}$, Febri Dwi Harianto ${ }^{7}$
}

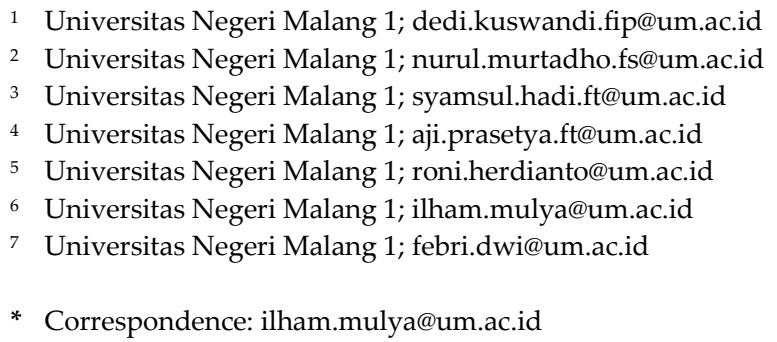

\begin{abstract}
Every scholarly journal's ultimate objective and purpose is to publish high-quality work. This article discusses the adoption of a worldwide virtual writing camp as an alternate approach given by journal editorial boards to increase the quality of prospective authors during the current Sars-Cov-2 pandemic, when face-to-face meetings are impractical. A virtually entire training program was designed for those interested in submitting their manuscript to journals but lack the necessary understanding and expertise to write a so-called high-quality paper. This strategy consisted of nine phases and required around three months to complete. By the end of the camp, participants should have written one or more papers that were ready to send and submit.
\end{abstract}

\section{Introduction}

For the last few decades, publishing scientific papers in scholarly journals has become an ever-increasing need for Indonesian academics. Writing a scientific report that is publishable demands a high level of expertise and talent [1], [2]. When authors write a scientific article, they must be able to collect accurate information regarding the content of the study and organize it using legible language and structure [2], [3]. Not to mention, writing a high-quality paper requires sophisticated literacy skills, specifically the ability to acquire and analyze information and generate ideas through effective writing. However, these characteristics are frequently lacking in authors, particularly when it comes to academic writing in order to create an accessible work [4] [5] [6]. When the authors submitted their paper(s), they frequently assumed what they had written in the article. Numerous authors underestimated the importance of writing quality due to a lack of exposure to academic discourse [2] [4] [6].

The primary objective of a scholarly journal is to publish legible and standardized articles, which is critical. Editorial boards are responsible for ensuring the quality of papers published in the journal [7]. The journal editor has been, and continues to be, the standard bearer for peer-reviewed scientific publications, basically deciding whether or not to publish a work [8]. Unfortunately, journal editors are faced with a problem when selecting whether to advance papers to the next stage of review or accept them. Frequently, journal editors must decide whether to publish the article as-is (under the circumstance where the paper does not require significant change but still considered as low quality). Due to the fact that the quantity of manuscripts sent to the editorial office was 
limited for each issue, this choice was preferred. As a result, journal editors must abandon the standard in order to address current concerns.

Indeed, the circumstance described above undermines the concept of academic publication as a vehicle for disseminating high-quality research - it is vital for scholarly journals to distribute scientific work in order to advance knowledge [9], [10]. In the near future, when journal editors abandon the standard of publication to the fullest extent possible, this may result in the journal's unprogressive development as the principal conduit for disseminating scientific knowledge. In addition to this concept, the author's position in the journal is critical. Thus, it is critical for journal editors to embrace writers totally in order to ensure compliance with the standard (an worldwide standard) of publication through author training. In most situations, prospective writers are at a loss for what to write and convey in their paper due to their lack of experience to scientific publication in journals as a student of higher education. Numerous students struggle to write readable manuscripts because they are oblivious to poor grammatical and sentence structure; misspelling inside the body of text; and collocations that are inappropriate for the context [11]. Additionally, due to cultural differences, the majority of students received insufficient exposure to the international norm for manuscript writing [3].

To ensure that the editorial office receives high-quality manuscripts, this article advises that potential authors receive complete writing instruction in order to ensure that their work meets the worldwide standard for publishing. This approach intends to provide students with a student-centered education in the context of research and publication, as they frequently lack practice in their classroom learning [12] [13]. Thus, thorough and in-depth training for potential writers is essential to improve manuscript quality, which benefits both authors and journal editors.

\section{Training Frameworks}

\section{General Overview of Training}

This article provides potential authors with instruction on how to properly write for and submit to scientific journals. The training was conducted in five interconnected and successive phases over a period of 20 weeks. In this research, the training phases are separated into three sections referred to as the ICE frameworks - Initial, Core, and Extensive. Initially, training would take place in face-to-face meetings in two distinct locations. However, due to the present global epidemic, which requires us to avoid direct engagement, including classroom instruction, the training was conducted via an online platform. It used Google Classroom and Google Meet since both platforms are accessible to all participants; this is owing to the popularity of the participants' Google Accounts. This training was conducted with international students enrolled in universities in the Malang area. Undergraduate and graduate students are eligible to participate. The following figure illustrates the training framework in its simplest form. 


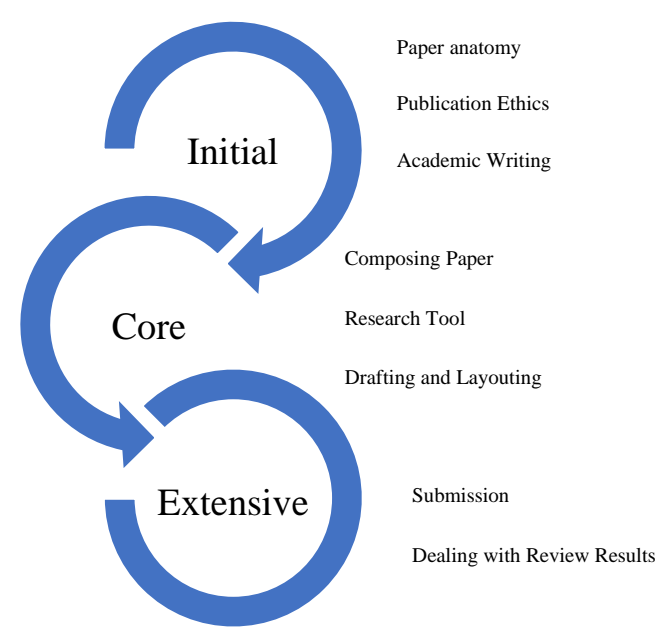

Figure1. The Framework of ICE (Initial, Core, Extensive)

\section{Training Phases}

To assist prospective authors, we propose five steps of training, each of which is interconnected, in order to increase the quality of article writing and overall comprehension of scholarly journals.

\section{Initial Phase of Training}

We attempted to identify common concerns and challenges associated with producing scientific papers during the early phase of training. We examined the most prevalent obstacles encountered by authors in general and attempted to determine how to overcome them through the subsequent steps of training. Additionally, we offer prospective authors with theoretical information and concepts about journals and scientific papers throughout this time. It includes a thorough understanding of the journal and the details involved in the process of writing a scientific article, such as the paper's anatomy, the 'do's and 'don'ts' of academic writing, academic writing grammar, previous research review, publication ethics, and how to discover good references. Prior to participants producing their own drafts, it is critical to educate them about the many parts of journal publication and scientific paper writing. To write a good paper that contains important fresh information, the writers must first comprehend what has been previously reported. Regrettably, this comprehension is frequently lacking among them. When participants get a sufficient comprehension of journal and scientific paper writing, it becomes quite simple for them to draft their own work [4]. After completing the first step, participants were invited to write about something they were passionate about.

\section{Core Phase of Training.}

The second phase of training is the first core training, which teaches learners how to write scientific papers in practice. During the preceding phase, participants are invited to brainstorm certain topics and themes that interest them. What has been prepared previously is developed during the second portion of instruction. During this phase, participants receive extensive coaching from editors who serve as trainers. This is the most critical phase. This phase is regarded the most critical because it addresses the fundamental issue of how to write a legible and high-quality paper. This stage enables participants to gain a thorough understanding of how to write an appropriate title for a scientific journal, how to write a concise and appropriate abstract that accurately summarizes the full research, how to write the introduction section and any other document anatomy. Along with paper anatomy writing, this phase teaches participants how to use certain important 
resources for research writing, such as a reference management and plagiarism detection software.

After the participants draft the article in the second phase with extensive mentoring from the editors, the work is edited and formatted to fulfill the journal's technical standards, such as paper template and plagiarism level. This course teaches participants how to consider several critical aspects required by the journal, including referencing style, table and figure layout, key title page information, and author information. These components appear to be insignificant. However, the majority of authors frequently disregard the journal's style and requirements. As a result, during the first submission procedure, the work is frequently rejected by the editorial office and does not continue immediately to the peer-review process.

\section{Extensive Phase of Training.}

The subsequent phase focuses on the paper submission process. When authors submit a paper to an academic publication, they must understand how the journal's system works. Each magazine makes use of a unique system and platform, ranging from the Open Journal System developed by the Public Knowledge Project, or PKP, to Web of Science's ScholarOne. Even some journals published by Elsevier have their own system, which varies slightly from one to the other. It is undeniable that maintaining a journal management system is a hard and time-consuming operation, and writers may overlook some elements during the submission process [14]. During this phase, the editors who serve as trainers provide participants with hands-on experience using journal management systems. This phase instructs participants to practice key elements such as user registration and metadata entry. These practices are critical for writers since, given the current state of paper submission, nearly all journals require authors to submit via their system. Finally, but certainly not least, is the process of dealing with the review outcomes. The review outcomes are a critical component of the manuscript submission process. Without a doubt, reviewers have established and dictated the quality for papers submitted to journals. Regrettably, when authors receive review results from reviewers (particularly when the manuscript requires significant revision), they are ill-equipped to cope with them. As a result, they spend more time revising. In the worst-case scenario, the authors reject the results and prefer to submit to another journal - which will likely take longer to process. When the authors obtain review results during this lengthy phase, the editors who serve as training instructors give them with practical understanding. It teaches them how to pay attention to which aspects of the article should be revised in light of the results.

\section{Concluding Remarks}

In today's academic discourse, publishing academic papers in journals is critical, especially for individuals who work in academic institutions (lecturers, experts, and/or college students) and wish to spread their findings and views. The procedure of publishing a manuscript in an academic publication has become increasingly complicated and timeconsuming. However, the majority of those involved in academic discourse do not pay close attention to each and every activity required - from paper creation to paper submission. The majority of editors got what are referred to as 'unsuitable' submissions. On that note, this work proposes a series of training procedures to assist potential authors prior to submitting their research findings to journals. This study proposes three divisible phases that are interrelated. This article proposes an ICE training structure for authors that includes Initial, Core, and Extensive training phases to help authors overcome common obstacles they may encounter while submitting their work to journals. 


\section{References}

[1] M. K. M. Singh, "International Graduate Students' Academic Writing Practices in Malaysia: Challenges and Solutions," J. Int. Students, vol. 5, no. 1, pp. 12-22, 2015.

[2] M. K. M. Singh, "Academic Reading and Writing Challenges Among International EFL Master's Students in a Malaysian University," J. Int. Students, vol. 9, no. 4, pp. 971-992, 2019.

[3] J. Turner, Language in The Academy: Cultural Reflexity and Intercultural Dynamics. Bristol: Buffalo: MUltilingual Matters, 2012.

[4] M. L. Gea-Valor, J. Rey-Rocha, and A. I. Moreno, "Publishing research in the international context: An analysis of Spanish scholars' academic writing needs in the social sciences," English Specif. Purp., vol. 36, no. 1, pp. 47-59, 2014, doi: 10.1016/j.esp.2014.05.001.

[5] K. Hryniuk, "Non-Native Writing for Anglo-American Journals: Challenges and Urgent Neegs," in Studies in Second Language Learning and Teaching, vol. 10, no. 2, Warsaw: Warsaw University Press, 2019, pp. 385-389.

[6] N. G. Cennetkusu, "International students' challenges in academic writing: A case study from a prominent U.S. university," J. Lang. Linguist. Stud., vol. 13, no. 2, pp. 309-323, 2017.

[7] L. Chiriboga, "The changing landscape of scientific publishing," J. Histotechnol., vol. 42, no. 3, pp. 95-97, 2019, doi: 10.1080/01478885.2019.1636554.

[8] S. Serpa, M. J. Sá, A. I. Santos, and C. M. Ferreira, "Challenges for the academic editor in the scientific publication," Acad. J. Interdiscip. Stud., vol. 9, no. 3, pp. 12-16, 2020, doi: 10.36941/ajis-2020-0037.

[9] C. Y. Wong, "A century of scientific publication: towards a theorization of growth behavior and researchorientation," Scientometrics, vol. 119, no. 1, pp. 357-377, Apr. 2019, doi: 10.1007/s11192-019-03048-5.

[10] G. Baffy et al., "Scientific Authors in a Changing World of Scholarly Communication: What Does the Future Hold?," Am. J. Med., vol. 133, no. 1, pp. 26-31, Jan. 2020, doi: 10.1016/j.amjmed.2019.07.028.

[11] M. R. Lea and B. V. Street, "Student Writing in Higher Education: An academic literacies approach," Stud. High. Educ., vol. 23, no. 2, pp. 157-172, 1998, doi: 10.1080/03075079812331380364.

[12] B. Paltridge, "Graduate Student Writing," in The TESOL Encyclopedia of English Language Teaching, Wiley, 2019, pp. 1-6.

[13] J. Swales and C. Feak, Academic writing for graduate students: Essential tasks and skills. 2004.

[14] S. Kim, H. Choi, N. Kim, E. K. Chung, and J. Y. Lee, "Comparative analysis of manuscript management systems for scholarly publishing," Sci. Ed., vol. 5, no. 2, pp. 124-134, 2018, doi: 10.6087/KCSE.137. 